https://doi.org/10.1590/198053146302

\title{
INFÂNCIAS E PESQUISAS EM BUSCA DE PEDAGOGIAS DESCOLONIZADORAS
}

\author{
Artur Oriel Pereira'
}

SANTOS, Solange Estanislau dos; SANTIAGO, Flávio; BARREIRO, Alex; MACEDO, Elina Elias de; FARIA, Ana Lúcia Goulart de (org.). Pedagogias descolonizadoras e infâncias: por uma educação emancipatória desde o nascimento. Maceió: Edufal; Imprensa Oficial Graciliano Ramos, 2018. 173p.

A construção de uma educação emancipatória que contemple a igualdade, o respeito e o reconhecimento das diversidades, que desconstrua perspectivas dominantes ao mesmo tempo que articula práticas transformadoras da condição de vida dos sujeitos, tem se tornado um grande desafio no contexto brasileiro contemporâneo. Deve-se estar atento às singularidades e especificidades que abrangem a educação, assim como há emergência do entendimento dos marcadores de diferença de raça, gênero, classe e idade que implicam as relações sociais produzidas continuamente, tendo em vista que a nossa sociedade competitiva permanece injusta, com desigualdade social extrema. Entre outras questões, é necessária uma análise crítica pós-colonialista dos discursos dominantes sobre as crianças, que refletem o conhecimento hegemônico das infâncias ou das crianças.

Nesse contexto, os/as organizadores/as Solange Estanislau dos Santos, Flávio Santiago, Alex Barreiro, Elina Elias de Macedo e Ana Lúcia Goulart de Faria, em seu livro Pedagogias descolonizadoras e infâncias: por uma educação emancipatória desde o nascimento, apresentam algumas provocações, debates e inquietações de intelectuais das mais variadas áreas do conhecimento, como da Filosofia, História, Ciências Sociais, dentre outras, comprometidos/as com a educação, que evidenciam a produção do conhecimento sul-sul preocupado com a desconstrução das amarras coloniais que perpassam as infâncias e colonizam os desejos e corpos das crianças desde bebês.

O livro é resultado das discussões ocorridas durante o "II Seminário Internacional sobre Infâncias e Pós-colonialismo: pesquisas em busca de pedagogias descolonizadoras”, realizado pelo Grupo de Estudos e Pesquisa em Educação e Diferenciação Sociocultural - linha Culturas Infantis, da Faculdade de Educação da Universidade Estadual de Campinas. Nesse evento, foram compartilhados dados de pesquisas sobre as experiências vividas pelas crianças, bem como a educação da/na infância, em contextos brasileiros nos quais tenham sido submetidas a condições opressivas, e também fora deles, como na experiência cubana, cuja 
educação desobedece às estruturas organizacionais marcadas por metas e supostas hierarquias de desenvolvimento cognitivo das crianças, típicas dos modelos de sociedade capitalista.

Os oito capítulos do livro nos colocam em contato com uma diversidade de tons textuais que compõem as tessituras de uma abordagem inspirada nos estudos pós-coloniais supondo outra paisagem, apontando para a (re)formulação do pensamento moderno, em oposição a toda e qualquer forma de hierarquização, pois isso implicaria a não transformação e mudança social. A obra serve, assim, como subsídio para combater a opressão e para a construção de uma pedagogia descolonizadora das infâncias que favoreça a compreensão das construções das desigualdades.

No prefácio intitulado "Fora do jogo pós-colonial”, Antonio Carlos Rodrigues de Amorim, pensando a representação no ponto crítico das teorias e práticas em educação, nos convida a se aproximar das crianças e da videoartista tunisiana Moufida Fedhila, cuja obra vem se destacando no cenário contemporâneo das artes visuais pós-coloniais. Com as dimensões trazidas “a partir do encontro com as crianças de uma obra visual de artista muitas vezes considerada ‘filha' da diáspora e partidária, [...] de políticas desejantes de novas identidades ou diferenças” (AMORIM, 2018, p. 11), somos impulsionados/as a refletir sobre os discursos de resistência, multiculturais, pós-coloniais, moventes e transversais, que problematizam a complexidade de se considerar a construção das subjetividades baseada apenas em um modelo universal humano.

Sob essa perspectiva, Miguel Arroyo, no capítulo "Descolonizar o paradigma colonizador da infância”, em tom de denúncia contra o colonialismo - que é uma experiência de brutal produção dos outros como subalternos, por meio do mito da inferioridade de origem, que os colocam como não reconhecidos humanos, logo não humanizáveis -, evidencia os modos de pensar as outras infâncias inseparáveis do modo de pensar seus coletivos, alertando que, para avançarmos em pedagogias descolonizadoras, é preciso, sobretudo, descontruir a concepção epistemológica de infância única. A partir do questionamento "que epistemologias do humano, da infância e da pedagogia descolonizar?”, Arroyo (2018, p. 32) destaca que "o pensamento pós-colonial obriga o pensamento pedagógico crítico a radicalizar a reconstrução histórica dos conflitos e nas formas de pensar os Outros e suas infâncias que perpassam toda nossa história da educação latino-americana”. Desse modo, discutindo sobre outros estudos da infância, podemos reconhecer a infância liberta dos preconceitos sexistas, racistas adultocêntricos, enxergando-a como sujeito de autogestão de seu percurso humano, de forma a articular os saberes da infância com os saberes do currículo, com foco nos processos sociais e culturais e produção da infância, reconhecendo que a diversidade de espaços produz infâncias diversas, bem como o lugar da infância nos movimentos sociais para entender essas infâncias.

Nessa investida de experimentar outras formas de materializar o pensamento, sem a pretensão de redigir um texto carregado de normas eurocêntricas e positivistas, Silvio Gallo, no capítulo "Ir junto: sobre os desafios de educar uma 
‘infância maior'”, toma como base as indagações do filósofo René Schérer, que, a partir de Charles Fourier, propõe a concepção de "infância maior”. O autor discute que a infância é uma invenção moderna produzida pelos/as adultos/as que a colonizam como um dispositivo de infância que infantiliza as crianças, colocando-as todas dentro da mesma forma de ser criança, e são essas configurações que impõem as maneiras de educar. Gallo (2018) ressalta que é nesse contexto que se pensa e se produz uma infância como menoridade, tutelada, tutorada e conduzida pelos/as adultos/as na sociedade. Ele indaga se "seremos capazes de descolonizar a infância, [...] de aprender com elas, de irmos juntos, traçando linhas de fuga possíveis a esse tutelamento da infância que, de sobra, tutela também a nós, adultos" (p. 68). Numa série de 20 fragmentos, o pesquisador promove um exercício de deslocamento do sujeito, da nossa posição de adultos/as, desnaturalizando também a compreensão de infância como herança da modernidade, na qual adultos/as e crianças em parceria, com base na noção de devir-criança como fuga, podem ter a possibilidade de lutar contra este dispositivo de infância.

Petronilha Beatriz Gonçalves e Silva, no capítulo "O sentimento, a compreensão de que se pertence à humanidade começa desde sempre”, aponta que as relações sociais, em tempos e espaços diferentes, resultam em processos educativos às experiências dos sujeitos, de distintas idades e grupos sociais, que vão percebendo e sincronicamente construindo o seu pertencimento à humanidade. No bojo desses processos sociais, as crianças "captam estereótipos que têm mantido hierarquias social, racial e aprendem a reproduzi-las ou a combatê-las" (p. 71). Provocando-nos com algumas questões para construirmos pedagogias descolonizadoras, a pesquisadora lança: "qual a nossa agenda? qual nossa agenda para educar crianças, e para nos reeducarmos em nossa humanidade?” (p. 82). Dessa maneira, Silva (2018) problematiza noções sobre acolhimento, preconceitos, migração, políticas e diretrizes educacionais para a educação das relações étnicos-raciais, apontando princípios para que sejam pensados, no âmbito da cidadania, a consciência histórica da diversidade, o fortalecimento de identidades e de direitos e ações educativas de combate ao racismo e às discriminações.

Como todas essas indagações nos remetem a um exercício descolonizador do pensamento, seguindo essa chave, ao discorrer sobre a relação entre infância e Filosofia, Walter Omar Kohan, no capítulo "A infância descolonizadora do tempo”, inspirado em Deleuze, Derrida, Lyortard, entre outros/as, nos provoca a pensar a "relação entre escola e tempo, nos tempos que habitam a escola e nos tempos que nos habitam quando habitamos a escola” (p. 94). Logo, precisamos descolonizar nossos tempos, pensamentos e as maneiras como os pensamentos habitam a temporalidade dentro e fora das escolas; assim, então, a infância seria descolonizadora e não colonizada, pelo menos em relação ao tempo.

Ainda sobre as diferentes formas de pensar e a discussão da pós-colonização da infância a partir do que seria próprio da infância, César Donizetti Pereira Leite, no capítulo "Territórios infantis: entre imagens e potências de pensamento”, destaca que existe a possibilidade de pensarmos na infância e nos territórios infantis como signo: 
[...] um dos exercícios poderia ser se aventurar na ideia de pensar na inexistência desse território-signo, a inexistência a princípio de uma ideia de infância, para que a partir disso fossemos forçados a pensar nas heterogeneidades das relações que constituem esse signo. (LEITE, 2018, p. 102)

Para exemplificar a ideia de signo e de aventura do pensamento, Leite (2018) apresenta uma experiência de trabalho realizada com crianças da educação infantil, na qual as próprias crianças produziram imagens a partir dos seus pensamentos e olhares, explorando seus corpos e pelas coletividades nos espaços de educação, incluindo em seus modos de ocupação de espaços a noção de multiplicidade, nos impulsionando também à reflexão sobre as crianças e a sua participação nas pesquisas.

Elina Elias de Macedo e Solange Estanislau dos Santos, no capítulo “A perspectiva pós-colonial e as pesquisas com crianças", discutem como as pesquisas com crianças estão fomentando a produção científica na área da educação infantil, trazendo para o debate que “a reviravolta epistemológica se dá fundamentalmente pelo fato de a criança ser vista como sujeito social, histórico e produtora de culturas, inserida na lógica capitalista e, consequentemente, alvo de processos colonizadores” (p. 115). As pesquisadoras problematizam que as pesquisas já não são mais as mesmas assim como as crianças, enfatizando que, a partir de novas direções, formas de pensar e agir, todos/as poderemos criar mecanismos para resistir às opressões do capitalismo, do colonialismo e do patriarcado, bem como construir possibilidades de descolonização das diferenças, porque descolonizar é produzir uma processualidade para emancipação.

Quando falamos em processos emancipatórios, não podemos perder de vista os avanços e retrocessos na área educacional, no que diz respeito às garantias que professoras e professores têm no respaldo legal para o desenvolvimento de propostas pedagógicas acerca das temáticas de gênero e sexualidade. Alex Barreiro e Flávio Santiago, no capítulo "Infância, educação e colonialidade: notas para um debate a respeito da ideologia de gênero", a partir de referenciais teóricos pós-coloniais e dispositivos legais, discutem a reação dos setores conservadores na sociedade brasileira contra a inserção das discussões de gênero na educação pública e o quanto os dados estatísticos sobre a violência contra mulheres e a população LGBT (lésbicas, gays, bissexuais e transgêneros) estão sendo ignorados por essa ala política, uma vez que "as reações conservadoras como um discurso de reiteração e permanência da ordem colonial, impossibilitam o deslocamento dos sujeitos, [...] das crianças, compreendidas como incapazes de autodecisão e tomadas como um vir a ser” (p. 143), algo que vem desmantelando as políticas públicas nesse campo de ação.

Nesse contexto das discussões de cunho político, econômico e cultural de uma sociedade que se pretende democrática e alicerçada na justiça social, Maria Walburga dos Santos, no capítulo “Colonizações cotidianas: crianças e educação”, provocando o debate, traz uma reflexão sobre os princípios de dignidade, 
equidade, solidariedade, liberdade, respeito e ética ao tratar de exemplos da colonização cotidiana com as crianças pequenas, das relações étnico-raciais, de gênero, em dois cenários de pesquisa, no espaço urbano e numa comunidade quilombola. Nessa empreitada, Santos (2018, p. 160) aponta que "a resistência e os processos de descolonização perpassam pelas escolhas políticas, sociais, culturais, em qualquer tempo histórico e sociedade, e pela compreensão de que liberdade e dignidade são premissas do debate por justiça social”. Portanto, ao destacar a resistência dos grupos sociais minoritários e suas culturas, lança-se uma crítica sobre o direito à diferença e o adultocentrismo como forma de colonialismo.

O livro aqui apresentado expõe diferentes pontos de vista que, reunidos, formam um mosaico de estudos pós-coloniais contrários às pedagogias escolarizantes, que estratificam as crianças e negociam o ensino-aprendizagem. Suas linhas são tecidas como investidas transversais que visam aos diferentes saberes na produção do pensamento plural e emancipador para a educação infantil e anos iniciais do ensino fundamental. A obra contribui para o debate educacional, sobretudo a respeito dos processos de construção de pedagogias macunaímicas e descolonizadoras, que constroem seus movimentos em outras, em novas direções e que nos ajudam na elaboração de uma educação emancipadora desde o nascimento.

\section{REFERÊNCIAS}

AMORIM, Antonio Carlos Rodrigues de. Fora do jogo pós-colonial. In: SANTOS, Solange Estanislau dos et al. (org.). Pedagogias descolonizadoras e infâncias: por uma educação emancipatória desde o nascimento. Maceió: Edufal; Imprensa Oficial Graciliano Ramos, 2018. p. 9-12.

ARROYO, Miguel. Descolonizar o paradigma colonizador da infância. In: SANTOS, Solange Estanislau dos et al. (org.). Pedagogias descolonizadoras e infâncias: por uma educação emancipatória desde o nascimento. Maceió: Edufal; Imprensa Oficial Graciliano Ramos, 2018. p. 27-58.

GALLO, Silvio. Ir junto: sobre os desafios de educar uma "infância maior". In: SANTOS, Solange Estanislau dos et al. (org.). Pedagogias descolonizadoras e infâncias: por uma educação emancipatória desde o nascimento. Maceió: Edufal; Imprensa Oficial Graciliano Ramos, 2018. p. 59-70.

KOHAN, Walter Omar. A infância descolonizadora do tempo. In: SANTOS, Solange Estanislau dos et al. (org.). Pedagogias descolonizadoras e infâncias: por uma educação emancipatória desde o nascimento. Maceió: Edufal; Imprensa Oficial Graciliano Ramos, 2018. p. 85-98.

LEITE, César Donizetti Pereira. Territórios infantis: entre imagens e potências de pensamento. In: SANTOS, Solange Estanislau dos et al. (org.). Pedagogias descolonizadoras e infâncias: por uma educação emancipatória desde o nascimento. Maceió: Edufal; Imprensa Oficial Graciliano Ramos, 2018. p. 99-114.

MACEDO, Elina Elias de; SANTOS, Solange Estanislau dos. A perspectiva pós-colonial e as pesquisas com crianças. In: SANTOS, Solange Estanislau dos et al. (org.). Pedagogias descolonizadoras e infâncias: por uma educação emancipatória desde o nascimento. Maceió: Edufal; Imprensa Oficial Graciliano Ramos, 2018. p. 115-124.

SANTOS, Maria Walburga dos. Colonizações cotidianas: crianças e educação. In: SANTOS, Solange Estanislau dos et al. (org.). Pedagogias descolonizadoras e infâncias: por uma educação emancipatória desde o nascimento. Maceió: Edufal; Imprensa Oficial Graciliano Ramos, 2018. p. 147-164. 
SANTOS, Solange Estanislau dos; SANTIAGO, Flávio; BARREIRO, Alex; MACEDO, Elina Elias de; FARIA, Ana Lúcia Goulart de (org.). Pedagogias descolonizadoras e infâncias: por uma educação emancipatória desde o nascimento. Maceió: Edufal; Imprensa Oficial Graciliano Ramos, 2018. 173p.

SILVA, Petronilha Beatriz Gonçalves e. O sentimento, a compreensão de que se pertence à humanidade começa desde sempre. In: SANTOS, Solange Estanislau dos et al. (org.). Pedagogias descolonizadoras e infâncias: por uma educação emancipatória desde o nascimento. Maceió: Edufal; Imprensa Oficial Graciliano Ramos, 2018. p. 71-84.

\section{COMO CITAR ESTA RESENHA}

PEREIRA, Artur Oriel. Infâncias e pesquisas em busca de pedagogias descolonizadoras. Cadernos de Pesquisa, São Paulo, v. 49, n. 174, p. 340-345, out./dez. 2019. [Seção] Resenhas. Resenha da obra de: SANTOS, Solange Estanislau dos; SANTIAGO, Flávio; BARREIRO, Alex; MACEDO, Elina Elias de; FARIA, Ana Lúcia Goulart de (org.). Pedagogias descolonizadoras e infâncias: por uma educação emancipatória desde o nascimento. Maceió: Edufal; Imprensa Oficial Graciliano Ramos, 2018. 173p. https://doi. org/10.1590/198053146302 